\title{
Renal cell carcinoma in children and young adults: analysis of clinicopathological, immunohistochemical and molecular characteristics with an emphasis on the spectrum of Xp11.2 translocation-associated and unusual clear cell subtypes
}

\author{
A Wu, ${ }^{1}$ L P Kunju, ${ }^{1}$ L Cheng ${ }^{3} \&$ R B Shah ${ }^{1,2}$ \\ Departments of ${ }^{1}$ Pathology and ${ }^{2}$ Urology, University of Michigan School of Medicine, Ann Arbor, MI, and ${ }^{3}$ Department of \\ Pathology, Indiana University School of Medicine, Indianapolis, IN, USA
}

Date of submission 24 April 2008

Accepted for publication 28 May 2008

Wu A, Kunju L P, Cheng L \& Shah R B

(2008) Histopathology 53, 533-544

Renal cell carcinoma in children and young adults: analysis of clinicopathological, immunohistochemical and molecular characteristics with an emphasis on the spectrum of Xp11.2 translocation-associated and unusual clear cell subtypes

Aims: Recent studies suggest that paediatric renal cell carcinoma (RCC) may represent a distinct group of tumours; however, its biological behaviour and classification remain poorly understood. The aim was to analyse 13 RCCs from patients $\leq 23$ years of age to determine their clinicopathological, immunohistochemical and molecular characteristics.

Methods and results: The histological spectrum included: Xp11.2 translocation-associated (6/13 patients, $46 \%)$, clear cell $(5 / 13$ patients, $38 \%)$, papillary $(1 / 13$ patients) and unclassified (1/13 patients) types. The Xp11.2 translocation-associated RCCs had a wide morphological spectrum, with high nuclear grade cells with abundant cytoplasm ranging from clear to granular and architecture ranging from solid to papillary.
These tumours lacked cytokeratin expression and were confirmed by nuclear reactivity for TFE3 protein. Most of these translocation-associated tumours presented at high stage and had an unfavourable outcome. Three clear cell RCCs had unusual features that have not been previously characterized, including solid and cystic architecture, cells with abundant eosinophilic cytoplasm yet low nuclear grade and focal cytoplasmic inclusions, resembling oncocytoma. Deletion of subtelomeric 3p25 was observed in two of these RCCs.

Conclusions: Xp11.2 translocation-associated RCC represents a predominant and aggressive subtype in the paediatric age group. Increased awareness of this subtype is important due to its heterogeneous morphology.

Keywords: renal cell carcinoma in children and young adults, TFE3, Xp11.2 translocation-associated renal cell carcinoma

Abbreviations: AMACR, $\alpha$-methylacyl CoA racemase; BMT, bone marrow transplant; CA, carbonic anhydrase; CK, cytokeratin; EMA, epithelial membrane antigen; FISH, fluorescence in situ hybridization; FN, Fuhrman nuclear; IL, interleukin; PCKD, polycystic kidney diseases; RCC, renal cell carcinoma; vHL, von Hippel Lindau; WHO, World Health Organization

\section{Introduction}

Renal cell carcinoma (RCC) accounts for $90 \%$ of renal tumours in adults, with a peak occurrence in the sixth decade, and is the sixth most common cause of cancer-related death in the USA. In contrast, RCC in childhood is relatively rare, accounting for approximately $6 \%$ of malignant paediatric tumours and $<4 \%$

Address for correspondence: Rajal B Shah MD, Associate Professor of Pathology and Urology, University of Michigan, 1500 East Medical Center Drive, 2 G332 UH, Ann Arbor, MI 48109, USA. e-mail: rajshah@umich.edu 
of paediatric renal tumours. ${ }^{1-3}$ Genetic, immunohistochemical and histological data have led to the reclassification of RCC in the last decade. ${ }^{4}$ Recent evidence has indicated that paediatric RCC is a distinct entity with important clinical and prognostic associations. Paediatric RCC lacks the male:female gender predilection as well as associations with environmental factors that are often present in adult RCC. ${ }^{1,5,6}$ Whereas local lymph node metastases are a poor prognostic indicator in adult RCC, some studies have suggested a good outcome for paediatric RCC despite lymph node metastases. ${ }^{7,8}$

In addition, paediatric RCC is histopathologically and genetically distinctive. Unusual subtypes of RCC have been described, predominantly among children and young adults. A relatively novel paediatric RCC that is defined by its distinctive translocation has been coined the Xp11.2 translocation carcinoma. These tumours most commonly harbour either $t(X$; 17)(p11.2;q25), which leads to a fusion of the transcription factor gene TFE3 with the ASPL gene; $\mathrm{t}(\mathrm{X} ; 1)(\mathrm{p} 11.2 ; \mathrm{p} 34)$, which leads to the fusion of the TFE3 gene with the PSF gene; or $\mathrm{t}(\mathrm{X} ; 1)(\mathrm{p} 11.2 ; \mathrm{q} 21)$, which leads to a fusion of the TFE3 gene with the PRCC gene. ${ }^{4,9}$ Morphologically, these tumours have nested to pseudopapillary patterns, distinctive voluminous eosinophilic to clear cytoplasm and numerous psammoma bodies. ${ }^{10,11}$ A recently developed antibody for the immunohistochemical identification of TFE3 protein, which is thought to be constitutively overexpressed in these carcinomas, has been shown to be a highly sensitive and specific marker in these carcinomas. $^{12}$

Despite the evidence that paediatric RCC is distinct from adult RCC, there have been relatively few published series of paediatric RCC. ${ }^{1,2,5,7,8,13-15}$ Some of these studies were also reported before the introduction of the 2004 World Health Organization (WHO) classification, when Xp11.2 translocation-associated RCC was proposed as a distinct molecular subtype. ${ }^{1,14}$ In this study we retrospectively analysed a series of 13 RCCs occurring in children and young adults to delineate further the clinical, gross, morphological, immunohistochemical and molecular features of RCC in this age group.

\section{Materials and methods}

CASE SELECTION

The files of the Department of Pathology at University of Michigan were searched for all radical or partial nephrectomies with a diagnosis of RCC in patients $\leq 23$ years of age between January 1986 and June 2006. An age cut-off of 23 years was chosen because it is similar to that used in other series. ${ }^{2}$ None of these cases has been previously reported. All haematoxylin and eosin-stained sections were reviewed (R.B.S., L.P.K. and A.W.). All RCCs were assigned a Fuhrman nuclear (FN) grade ${ }^{16}$ and were classified using criteria proposed in the 2004 WHO classification. ${ }^{4}$ Tumours classified as Xp11.2 translocation-associated carcinomas had previously described morphological features ${ }^{9-11,17}$ and were immunohistochemically positive for TFE3 protein expression. ${ }^{12}$ All cases were staged according to the 2002 American Joint Committee on Cancer TNM staging system. ${ }^{18}$ Multiple additional pathological parameters including tumour size, architecture, cytoplasmic characteristics, presence of foamy macrophages, necrosis, focality and laterality were recorded for the study cases. In addition, demographic data (age, sex) and follow-up information (presence of recurrence, metastasis or death) were obtained from available clinical charts.

\section{IMMUNOHISTOCHEMISTRY}

Representative paraffin-embedded tissue blocks were selected in all cases for immunohistochemistry, which was performed using an avidin-biotin-peroxidase complex technique. In one case (case 8), representative blocks were not available for immunohistochemistry. When available, immunohistochemistry previously performed during the initial diagnosis of each case was reviewed.

An extended immunohistochemical panel including pan-cytokeratin (CK) cocktail [AE1/3 (Chemicon International, San Diego, CA, USA), 1:800; Cam5.2 (BD Biosciences, San Jose, CA, USA), 1:20, $30 \mathrm{~min}$ ], CAM 5.2 (BD Biosciences, 1:1, $30 \mathrm{~min}$ ), epithelial membrane antigen (EMA; Dako, Carpinteria, CA, USA; 1:25, $30 \mathrm{~min}$ ), CK7 (Dako; 1:125, $30 \mathrm{~min}$ ), CD10 (Vector Laboratories, Burlingame CA, USA; 1:10, $30 \mathrm{~min}$ ), RCC (Novocastra, Newcastle, UK; 1:100, $30 \mathrm{~min}$ ), WT1 (Cell Marque, Rocklin, CA, USA; 1:50, 30 min), HMB45 (Dako; 1:25, $30 \mathrm{~min}$ ), $\alpha$-methylacyl CoA racemase (AMACR; P504S) (Zeta Corporation, Tucson, AZ, USA; 1:20, $30 \mathrm{~min}$ ) and TFE3 (Santa Cruz, Santa Cruz, CA, USA; 1:80, $45 \mathrm{~min})$ was performed. Carbonic anhydrase IX (CA IX; Novus Biologicals, Littleton, CO, USA; 1:200, $30 \mathrm{~min}$ ) immunohistochemistry, a marker that has previously been described as relatively specific for clear cell carcinoma, ${ }^{19-21}$ was performed on selected cases with unusual morphology that were initially considered unclassifiable. Three authors (A.W., L.P.K. and R.B.S.) interpreted the immunohistochemistry 
results, which were scored as positive when $>10 \%$ of tumour cells demonstrated strong reactivity with the antibody. For TFE immunohistochemistry, moderate to strong nuclear reactivity in tumour cells was considered to be a positive reaction.

\section{MOLECULAR/CYTOGENETIC ANALYSIS}

Fresh tissue on three tumours was sent for conventional cytogenetic karyotype analysis. One sample was insufficient for analysis and another was determined to have a normal karyotype, leaving one tumour with cytogenetic data included in this study.

Fluorescence in situ hybridization (FISH) analysis to detect deletion of $3 p$ was performed on three RCCs with unusual morphology that were initially considered unclassifiable. The FISH procedure and analysis have been previously described in detail. ${ }^{22,23}$ FISH was performed with centromeric $\alpha$-satellite DNA probes for CEP3 (Spectrum Orange) and for the subtelomeric probe for 3p25 (3pTel25, Spectrum Green). All of the probes were obtained from Vysis (Downers Grove, IL, USA) and were diluted with tDenHyb 2 (CEP3-3pTel25) (Insitus, Albuquerque, NM, USA) in a ratio of 1:100. The resulting slides were examined by one of the study authors using a Zeiss Axioplan 2 microscope (Zeiss, Göttingen, Germany) with the following filters from Chroma (Chroma, Brattleboro, VT, USA): SP-100 4'-6-diamidino-2-phenylindole, fluorescein isothiocyanate MF-101 for Spectrum Green (subtelomeric 3pTel25) and Gold 31003 for Spectrum Orange (CEP3). The images were acquired with a charge coupled device camera and analysed with METASYSTEM ISIS Software (MetaSystem, Belmont, MA, USA). Five sequential focus stacks with 0.4-mm intervals were acquired and then integrated into a single image in order to reduce thickness-related artefacts.

The patients diagnosed with von Hippel Lindau (vHL) syndrome were determined as heterozygous or homozygous for vHL mutations through direct DNA sequencing of whole blood performed at the Children's Hospital of Philadelphia.

\section{Results}

\section{CLINICAL FEATURES}

Overall, 13 cases of RCC were diagnosed in patients $\leq 23$ years old from 1986 to 2006 at our institution, accounting for $<1 \%$ of all RCCs diagnosed at our institution during this time period. In this cohort, nine patients were male and four female and their ages ranged from 9 to 23 years (mean 17 years, median
17 years). The most common clinical presentations were haematuria $(n=4)$; family history of vHL syndrome or symptoms associated with vHL syndrome, such as liver or pancreatic cysts or hearing loss $(n=2)$; abdominal pain $(n=2)$; or incidentally found renal tumour on imaging studies $(n=2)$. One patient had a history of hepatoblastoma and was post chemotherapy, and another had tuberous sclerosis and polycystic kidney disease. Five patients underwent partial nephrectomy and eight underwent radical nephrectomy. The clinical features of the patients are summarized in Table 1.

CLINICOPATHOLOGICAL, IMMUNOHISTOCHEMICAL AND MOLECULAR FEATURES OF RCC SUBTYPES

Histologically, 13 RCCs were divided into five distinct subgroups: Xp11.2 translocation-associated RCC (6/13 cases, $46 \%)$; clear cell RCC $(5 / 13$ cases, $38 \%)$, vHL syndrome-associated $(n=2)$ and sporadic $(n=3)$; papillary RCC (1/13 cases); and RCC, unclassified (1/13 cases).

\section{Xp11.2 TRANSLOCATION-ASSOCIATED RCC}

Six cases $(46 \%)$ were classified as Xp11.2 translocation-associated RCCs. The ages of these patients were significantly lower (median age 13 years). Four were unifocal tumours; two consisted of two separate tumour nodules. Tumour sizes ranged from 35 to $110 \mathrm{~mm}$. Grossly, tumours were well defined, with yellow to tan-brown variegated cut surfaces, and had a cortical or subcapsular location, similar to clear cell RCC (Figure 1A). One tumour had white-tan, illdefined borders and arose primarily within the central portion of the renal parenchyma, possibly within a calyx, and projected into the renal pelvis. The majority of these tumours were extensively necrotic.

Morphologically, these tumours were predominantly composed of cells with voluminous cytoplasm that ranged from clear to eosinophilic. In most of the tumours, cell borders in some areas were prominent and bulging, giving rise to the previously coined 'soap bubble' morphology. ${ }^{9-11,17}$ Nuclear features within some tumours varied, from small, uniform nuclei to larger nuclei with prominent nucleoli. However, the highest FN grade in all tumours was 3. Architecturally, the tumours were heterogeneous, ranging from solid sheets, pseudoalveolae, trabeculae, pseudopapillae and true papillae. Four tumours (cases 1, 2, 3 and 4) had predominantly eosinophilic to clear cells in nests with a delicate intervening vascular network, mimicking clear cell RCC, and areas where the central cells within the 


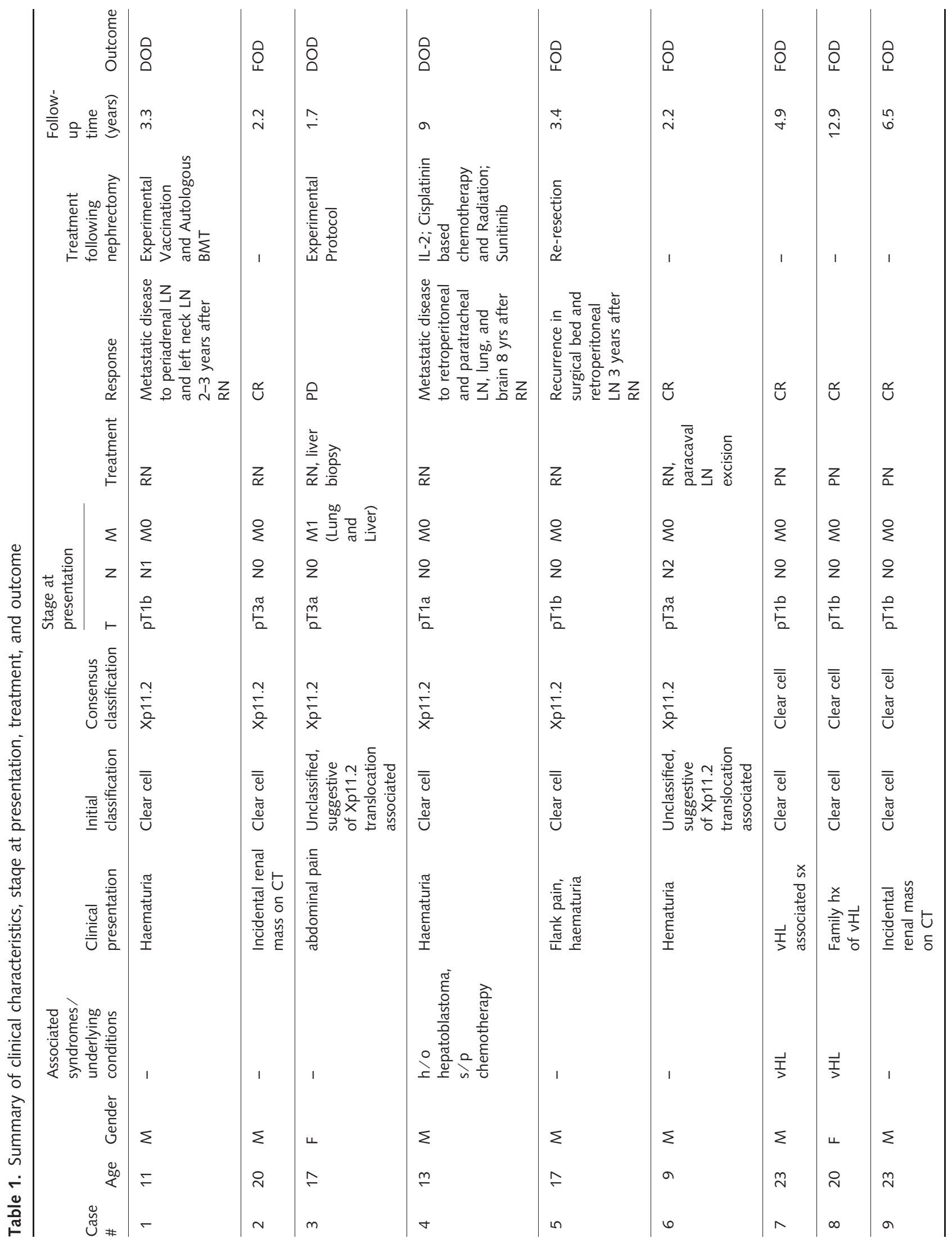




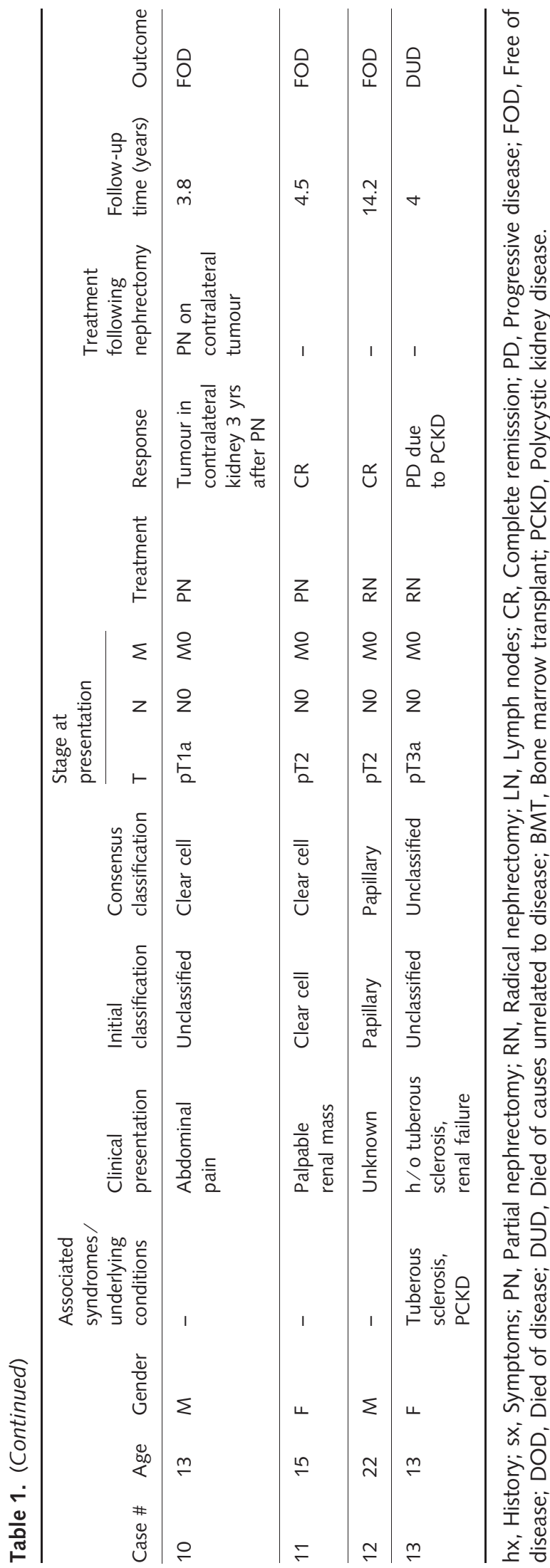

nests became discohesive, giving rise to a pseudoalveolar growth pattern. These four tumours also had a minor architectural pattern in which the cells were arranged around true fibrovascular cores, mimicking papillary RCC (Figure 1B,C,E). Of the remaining two tumours, one (case 5) was composed entirely of clear cells and was initially classified as a clear cell RCC; this tumour was reclassified 3 years after initial presentation when recurrent tumour with an entirely papillary architecture was biopsied, and TFE3 immunohistochemistry was performed. The sixth tumour (case 6) was composed entirely of eosinophilic cells arranged in papillae, resembling papillary type 2 carcinoma (Figure 1D), but was classified correctly at initial resection due to strong TFE3 protein overexpression. Two tumours had prominent, scattered psammoma bodies, and no tumours had xanthoma cells.

All of these tumours showed strong nuclear immunoreativity for TFE3 protein (Figure 1F), which has been shown to correlate with TFE3 gene fusion. ${ }^{12}$ In addition, despite some very focal positivity for CAM5.2 in a subset of tumours, all of the tumours were predominantly negative for cytokeratins. All tumours were also positive for CD10, RCC and AMACR. Details of the immunohistochemical results are summarized in Table 2.

Conventional karyotyping analysis was available in one case (case 3) and found a complex karyotype involving a translocation between Xp11.2 and 17q21: 55,X,t(X;17)(p11.2;q21),+der(1;12)(q10;q10),+2,i(2)(q10), der(3)t(3;17)(q29; 12$),+4,+8,+13,+14,+15$, +17 , $\operatorname{der}(17) \mathrm{t}(\mathrm{X} ; 17)(\mathrm{p} 11.2 ; \mathrm{q} 21),+20$. It is possible that the TFE 3 fusion partner corresponds either to the CLTC gene on $17 \mathrm{q} 23$, which has been recently reported ${ }^{24}$ or to some as yet undescribed gene.

CLEAR CELL RCC

Five cases $(38 \%)$ were classified as clear cell RCC; two arose in patients with vHL syndrome, whereas the remaining cases were sporadic. Clear cell carcinomas were more likely to arise in slightly older patients (median age 20 years). vHL-associated clear cell carcinomas were more likely than sporadic clear cell carcinoma to be multifocal. However, none were bilateral.

Three of the clear cell RCCs (two vHL-associated and one sporadic) had typical morphology, characterized by tumour cells with clear cytoplasm arranged in cords and trabeculae with a delicate intervening vascular stroma. These carcinomas also had prominent cystic change, although none were classified as a multilocular cystic RCC. All had a low FN grade (FN grade 2). 

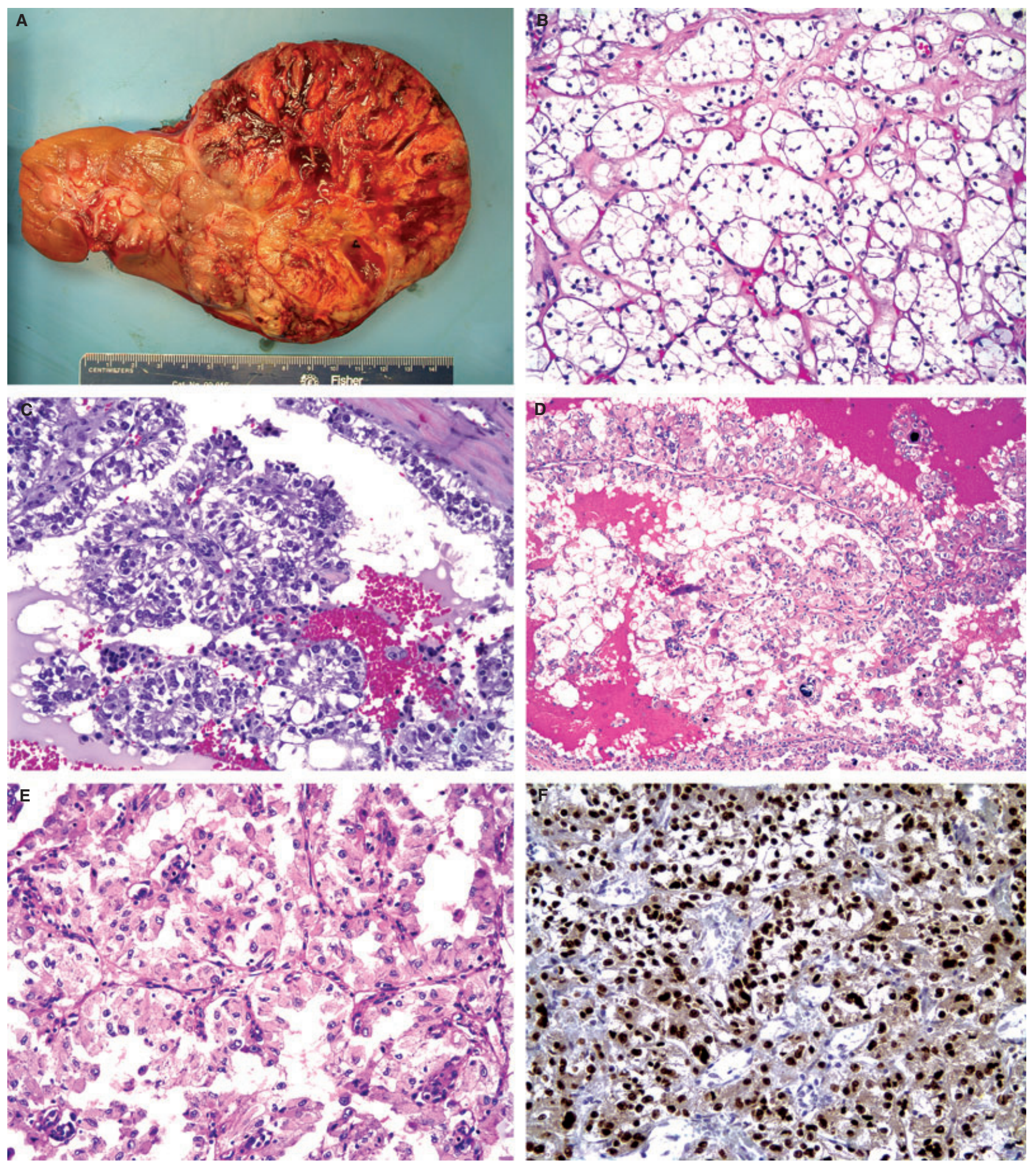

Figure 1. Xp11.2 translocation-associated renal cell carcinomas (RCCs) were predominantly well defined, cortical tumours with yellow to tan-brown variegated cut surfaces (A). These tumours predominantly had heterogeneous morphology; in areas of some tumours, the cells had abundant, clear cytoplasm with bulging cell borders, mimicking clear cell RCC (B). In other areas, these tumours formed well-defined papillae, mimicking papillary RCC (C). In fact, one tumour was completely papillary with prominent psammoma bodies and was morphologically indistinguishable from type 2 papillary RCC (D). Other areas of these tumours had eosinophilic cells arranged in nests in which the central cells became discohesive, giving rise to a pseudoalveolar pattern (E). All of these tumours showed strong nuclear reactivity by TFE immunohistochemistry (F). 
Table 2. Immunohistochemistry staining results for all Xp11.2 translocation associated renal cell carcinomas

\begin{tabular}{|c|c|c|c|c|c|c|c|c|c|c|}
\hline Case \# & CK Cocktail & Cam 5.2 & CK7 & EMA & CD10 & RCC & WT1 & HMB45 & AMACR & TFE3 \\
\hline 1 & - & Focal + & - & - & +++ & ++ & - & - & +++ & +++ \\
\hline 2 & - & - & - & - & +++ & +++ & - & - & + & +++ \\
\hline 3 & - & - & - & - & +++ & + & - & - & + & + \\
\hline 4 & - & Focal + & - & - & +++ & + & - & - & +++ & + \\
\hline 5 & - & - & - & - & +++ & + & - & - & ++ & + \\
\hline 6 & - & - & - & - & +++ & + & - & - & +++ & + \\
\hline
\end{tabular}

Two patients (cases 10 and 11) had clear cell RCCs with an unusual morphology that initially caused difficulty in classification. Since one patient had a tumour with identical morphology in the contralateral kidney 3 years after initial presentation, three tumours from these two patients were available for study. These carcinomas had large prominent cystic spaces that were lined by eosinophilic cells, which in some areas demonstrated hobnailing, focally mimicking cystic nephroma at low power (Figure 2A). In solid areas of these tumours, cells with abundant eosinophilic cytoplasm yet round regular nuclei without visible nucleoli were arranged in nests and tubules, focally mimicking oncocytoma. Scattered cells had prominent eosinophilic cytoplasmic inclusions (Figure 2B). These cases were positive for CD10, EMA and RCC and were negative for CK cocktail, CK7 and CAM5.2. All three tumours were strongly and diffusely positive for CA IX. (Figure 2C). Two of the three tumours demonstrated loss of one copy of subtelomeric 3p (Figure 2D). Given these results and the overall morphology of these tumours, they were classified as clear cell RCC.

\section{PAPILLARY RCC}

One 22-year-old patient presented with papillary RCC. The tumour had characteristic type 2 morphology, with cells with high FN grade, nuclear stratification, and abundant voluminous eosinophilic cytoplasm. The tumour was positive for cytokeratins, CD10 and AMACR and negative for TFE3.

\section{RCC, UNCLASSIFIED}

One patient was a 13-year-old girl with tuberous sclerosis and polycystic kidney disease who had a RCC arising within a background of angiomyolipoma. The RCC had a heterogeneous morphology; different areas resembled clear cell, papillary, or chromophobe RCC morphology. The areas of carcinoma were focally immunoreactive for CK cocktail and CAM5.2, strongly reactive for $\mathrm{CD} 10$ and $\mathrm{RCC}$ and were immunonegative for TFE3, whereas the angiomyolipoma component was strongly reactive for smooth muscle actin and HMB- 45 .

\section{CLINICAL STAGE AND OUTCOME}

\section{Stage at presentation}

The stage at presentation is summarized in Table 1. Of note, nearly all (four of six) of the Xp11.2 translocation-associated RCCs presented at higher stage. The clear cell RCCs and papillary RCC presented at low stage, whereas the unclassified RCC arising in the patient with tuberous sclerosis presented at higher stage.

\section{Outcome}

The median follow-up time was 4 years (mean followup time 5.6 years, range 1.7-14.2 years). Of the total of 13 patients, eight are currently free of primary disease without any evidence of recurrence after initial resection. These eight patients include two of the six Xp11.2 translocation-associated RCCs, the five clear cell RCCs and the papillary RCC. One patient with a clear cell RCC with unusual morphology (cells with eosinophilic cytoplasm and low-grade nuclei) had a pT1NOM0 tumour with identical morphology and immunohistochemical profile in the contralateral kidney 3 years after initial resection. This patient is currently disease free after a partial nephrectomy of the contralateral tumour.

Of the five remaining patients, one patient with an Xp11.2 translocation-associated RCC has had recurrent tumour in the surgical bed and retroperitoneal lymph nodes 3 years after initial resection, but is currently disease free following resection. 

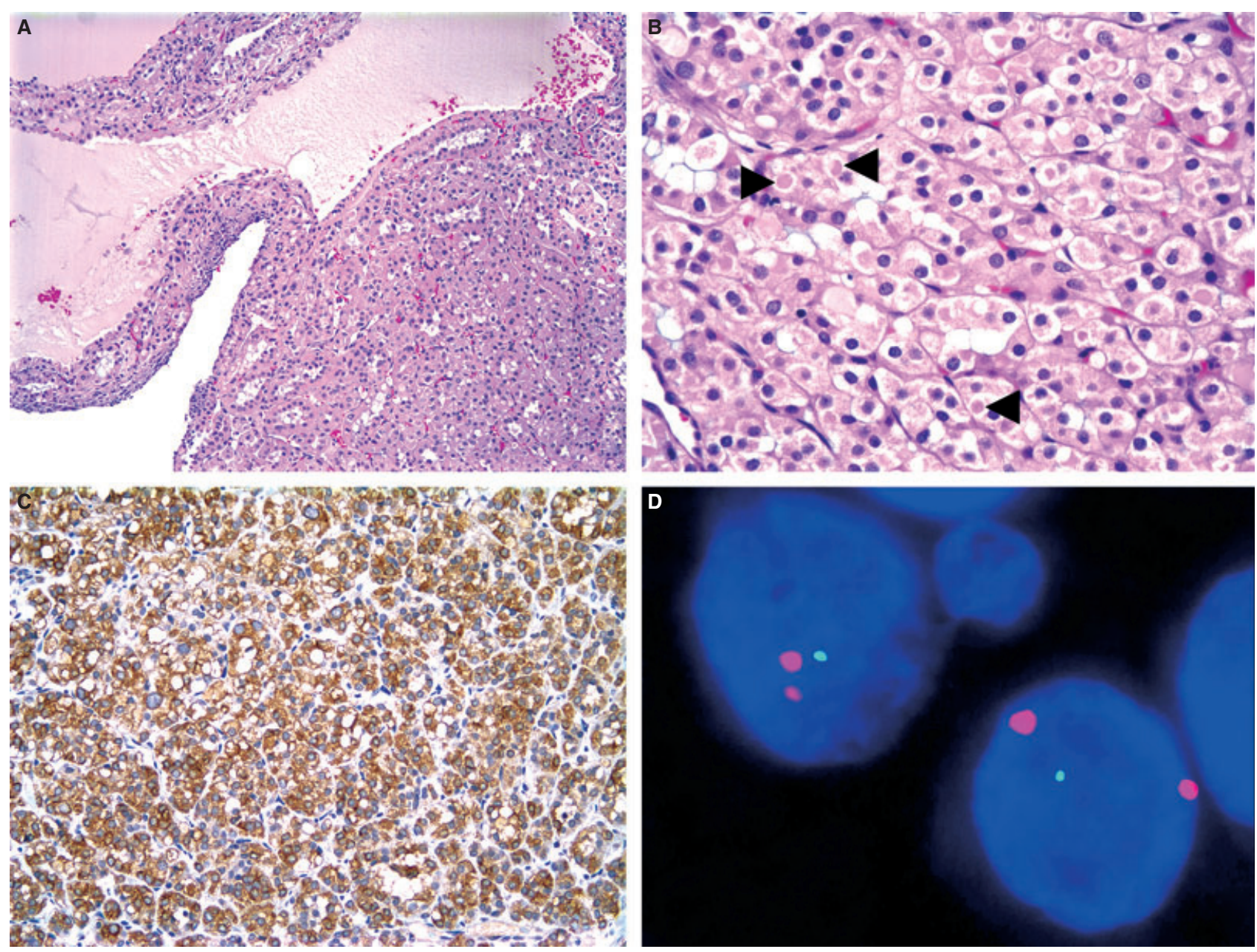

Figure 2. Three clear cell renal cell carcinomas (RCCs) have unusual morphological features, including large cystic spaces lined by eosinophilic cells which are focally hobnailed, superficially mimicking cystic nephroma (A), and cells with eosinophilic cytoplasm yet low nuclear grade with occasional prominent cytoplasmic inclusions (arrowheads), focally resembling oncocytoma (B). These RCCs were strongly positive for carbonic anhydrase IX (C), and two tumours show retention of two copies of centromeric 3p (Spectrum Orange) along with loss of one copy of subtelomeric 3p25 (Spectrum Green) (D).

The three patients who died of disease all had Xp11.2 translocation-associated RCC. Of these patients, one (case 4) presented with pT1NOMO disease and was thought to be disease free following resection, but had widespread metastatic recurrences 8 years after presentation. The second patient (case 1) had T1N1M0 disease, also thought to be completely resected, but had widespread metastatic recurrences 2 years after presentation. Despite numerous attempts at adjuvant therapy, including cisplatinin-based chemotherapy, interleukin (IL)-2 therapy, autologous bone marrow transplant and Sunitinib, both patients died of progressive tumour burden 9 and 3 years after initial presentation, respectively. The third patient (case 3) had distant metastases at presentation, was enrolled in an experimental protocol, but died 2 years after presenta- tion. The sites for distant metastases were lung, liver, brain, paratrachea and cervical and periadrenal lymph nodes.

Finally, the patient with tuberous sclerosis and polycystic kidney disease with unclassified RCC arising in a background of angiomyolipoma died of complications due to end-stage renal disease.

\section{Discussion}

RCC in children is a rare disease. ${ }^{3}$ In our series of 13 cases, RCC in this age group accounted for $<1 \%$ of all RCCs diagnosed over a 20-year span. Speculation remains whether paediatric RCC represents a truly different entity from its adult counterpart. ${ }^{1,5-8}$ Our results suggest that RCCs in this age group share many 
Table 3. Summary and comparison of incidence, clinical characteristics, stage, and outcome in recent Xp11.2 translocation associated renal cell carcinoma series and current series

\begin{tabular}{|c|c|c|c|c|c|c|c|c|c|c|}
\hline \multirow[b]{2}{*}{ Author } & \multirow[b]{2}{*}{$\begin{array}{l}\text { \# of Xp11.2/ } \\
\text { Total cases } \\
\text { of RCC }(\%)\end{array}$} & \multicolumn{2}{|c|}{$\begin{array}{l}\% \text { of Xp11.2 RCC } \\
\text { with associated } \\
\text { conditions (\%) }\end{array}$} & \multicolumn{2}{|c|}{$\begin{array}{l}\% \text { of } \mathrm{Xp} 11.2 \\
\text { RCC at low } \\
\text { versus high stage }\end{array}$} & \multirow{2}{*}{$\begin{array}{l}\text { Median } \\
\text { follow-up } \\
\text { time } \\
\text { (years) }\end{array}$} & \multicolumn{4}{|c|}{$\begin{array}{l}\% \text { of Xp11.2 RCC } \\
\text { with favorable versus } \\
\text { unfavorable outcome }\end{array}$} \\
\hline & & $\begin{array}{l}\text { History of } \\
\text { chemotherapy }\end{array}$ & $\begin{array}{l}\text { Other } \\
\text { conditions }\end{array}$ & $\begin{array}{l}\text { Organ } \\
\text { confined } \\
(I, I I)^{*}\end{array}$ & $\begin{array}{l}\text { Non-organ } \\
\text { confined } \\
(\text { III, IV)* }\end{array}$ & & ANED & AWD & DUD & DOD \\
\hline Bruder $^{2}$ & $8 / 41(20)$ & 25 & 13 & $\mathrm{~N} / \mathrm{A}$ & $\mathrm{N} / \mathrm{A}$ & $\mathrm{N} / \mathrm{A}$ & $\mathrm{N} / \mathrm{A}$ & $\mathrm{N} / \mathrm{A}$ & $\mathrm{N} / \mathrm{A}$ & $\mathrm{N} / \mathrm{A}$ \\
\hline Geller ${ }^{7,15}$ & $10 / 12(83)$ & 0 & 0 & 30 & 70 & 2.6 & $\mathrm{~N} / \mathrm{A}$ & $\mathrm{N} / \mathrm{A}$ & $\mathrm{N} / \mathrm{A}$ & $\mathrm{N} / \mathrm{A}$ \\
\hline Altinok ${ }^{32}$ & $6 / 8(75)$ & 17 & 0 & 67 & 33 & 5.8 & \multicolumn{2}{|c|}{$100^{* *}$} & 0 & 0 \\
\hline Ramphal $^{27}$ & $7 / 13(54)$ & 14 & 0 & 57 & 43 & 3.3 & 86 & 0 & 0 & 14 \\
\hline Selle $e^{13}$ & $11 / 49(22)$ & 9 & 18 & 33 & 67 & 3.5 & 91 & 9 & 0 & 0 \\
\hline Geller $^{8}$ & $7 / 11(64)$ & 14 & 0 & 14 & 86 & 4 & 28 & 14 & 14 & 43 \\
\hline Current Study & $6 / 13(46)$ & 17 & 0 & 33 & 67 & 2.8 & 50 & 0 & 0 & 50 \\
\hline
\end{tabular}

$\mathrm{N} / \mathrm{A}$, Not applicable, information not reported; ANED, Alive with no evidence of disease; AWD, Alive with disease; DUD, died of causes unrelated to disease; DOD, Died of disease.

*Per the 2002 AJCC TNM staging system ${ }^{18}$; **Information regarding disease status in surviving patients not reported.

similarities to those in adults, yet possess some distinct clinicopathological characteristics. Contrary to other paediatric RCC series, we did find a male predominance (male: female ratio 2:1), similar to that described in adult RCC. ${ }^{1-3}$

Although several previous series of paediatric RCC do not mention any unusual or underlying syndromes, ${ }^{7,14}$ other series ${ }^{2,13}$ report approximately $20-30 \%$ of patients with underlying predisposing conditions or syndromes, such as a history of chemotherapy, neuroblastoma/teratoma, renal failure or tuberous sclerosis. In our series one of the interesting features was the association of two clear cell RCCs with vHL syndrome. Although the reported age of presentation of vHLassociated RCC is much younger than that reported in sporadic RCC (mean age of onset 37 versus 61 years), ${ }^{4}$ in the majority of the previously published paediatric series, vHL-associated RCC has not been reported. ${ }^{2,5,7,13,14}$ The ages of the vHL patients in our series were 20 and 23 years, again confirming that patients with vHL syndrome present with RCC at much younger ages. Two other patients had an underlying condition: one had a history of hepatoblastoma at 1 year old, underwent resection and cisplatinin and adriamycin chemotherapy and radiation, and subsequently developed an Xp11.2-associated RCC 12 years later. This case supports the reported association of approximately $10-15 \%$ of translocation RCC with prior exposure to cytotoxic chemotherapy. ${ }^{8,17,25-28}$ Finally, similar to other paediatric RCC series, we had one patient with tuberous sclerosis who had a RCC, unclassified type, arising in the setting of multiple angiomyolipomas. ${ }^{2,13}$

The reported incidence of the clear cell RCC subtype in paediatric patients has ranged significantly from low (6-15\%) to high (45-61\%), in comparison with that in adults of $80-90 \%{ }^{2,5,7,13,14}$ Clear cell RCC accounted for $38 \%$ of our tumours, a much lower incidence than that reported in adults. Interestingly, three clear cell RCCs from two patients presented with unusual morphological features that have not been previously described and have probably been classified as RCC, unclassified type, in other series. ${ }^{2}$ These cases had an unusual morphology that initially caused difficulty in their classification. These carcinomas were relatively circumscribed and had large prominent cystic spaces that were lined by eosinophilic cells, which in some areas demonstrated hobnailing, focally mimicking cystic nephroma at low power (Figure 2A). Despite the fact that eosinophilic cells within clear cell RCCs generally have higher FN grade, ${ }^{29}$ in the solid areas of our tumours the cells had abundant eosinophilic cytoplasm, yet round regular low-grade nuclei without visible nucleoli. Cells were arranged in nests and tubules, focally mimicking oncocytoma (Figure 2B). Scattered cells had prominent eosinophilic cytoplasmic inclusions. All tumours were confined to the organ. 
These RCCs were negative for cytokeratins and positive for CD10, EMA, RCC and CA IX (Figure 2C), a marker previously described to be relatively specific for clear cell RCC. ${ }^{19-21}$ Molecular analysis by FISH demonstrated loss of one copy of subtelomeric $3 p$ in two of the three cases, supporting the diagnosis of clear cell RCC in these cases (Figure 2D).

Xp11.2 translocation-associated RCC has been recently proposed in the new WHO classification as a distinct molecular subtype of RCC with a predilection for paediatric patients, although they are now increasingly being reported in adults., 40,31 This subtype is now thought to represent a significant proportion of RCC in paediatric patients, with widely divergent incidences reported in recent series $(20-75 \%)^{2,8,13,27,32}$ In our series, Xp11.2 translocation-associated RCC was the most common subtype, accounting for $46 \%$ of our tumours. The median age of these patients was only 13 years.

There is controversy relating to the biological behavior of RCC in children and young adults. Whereas some series have suggested a good prognosis, others report that prognosis is dependent on the overall stage of the tumour and completeness of resection similar to that seen in adult patients. ${ }^{5,6,13,14,33}$ In their series of 13 patients, Geller et al. found that four children with lymph node-positive RCC and without distant metastatic disease had a very favourable long-term prognosis. ${ }^{7}$ Some early and smaller series have reported a relatively indolent course in patients with translocation-associated RCC. ${ }^{11,27}$ However, in a recent paper by Geller et al., a literature search of TFE+ RCC series found that TFE+ RCC are much more likely to present at higher stage (III/IV) compared with TFE- RCC. They also found, however, that 14 of $15 \mathrm{~N}+\mathrm{M} 0$ TFE3+ RCC patients remain disease free with a median followup of 4.4 years, and therefore argue that local lymph node metastases in the absence of haematogenous disease spread does not necessarily portend a worse prognosis, at least in the short term. ${ }^{8}$ Complicating these data is that fact that there have been several case reports of recurrences occurring as long as 2030 years after initial resection of translocation-associated RCC. ${ }^{28,34,35}$

In our series the majority (four of six) of Xp11.2 translocation-associated RCCs presented at an advanced stage. The majority also had a poor outcome, with distant metastases and/or death, often occurring years after initial presentation. However, of note, stage at presentation and completeness of initial resection did not necessarily correlate with prognosis. For example, two patients initially presented with pT1NOM0 tumours and were thought to be disease free following resection, but developed widespread recurrences 38 years after presentation. One patient with pT1N1M0 disease, thought to be disease free after resection, died of recurrent disease 3 years after presentation. There were two patients who presented with relatively highstage tumours (pT3NOMO and pT3N2MO) who are currently disease and recurrence free. In addition, although our sample size is small, the absence of haematogenous metastases did not seem to correlate with better prognosis. In fact, in our series only one patient presented with distant metastases; indeed, this patient died of her disease 2 years after presentation. However, of the five remaining patients with either NOM0 or N+M0 disease, three either died from their disease or had widespread recurrences years after initial presentation. Indeed, it may be that initial stage at presentation, completeness of resection, or presence or absence of haematogenous metastases may be less important in predicting long-term prognosis in translocation-associated RCC than some as yet undefined underlying marker of tumour biology. Table 3 summarizes the incidence, clinical findings, stage and outcome of Xp11.2 translocation-associated RCCs described in our study and in recent paediatric RCC series.

The Xp11.2 translocation-associated RCCs in our series were resistant to conventional adjuvant therapies (cisplatinin-based regimens, IL-2 therapy and autologous bone marrow transplants). However, given our small sample size, as well as the fact that only a minority of clear cell RCCs are responsive to IL-2, it is still unclear whether translocation-associated RCCs are more resistant to adjuvant therapy than other histological subtypes. Nevertheless, the strikingly different prognosis between clear cell and papillary RCCs and Xp11.2 translocation-associated RCCs, along with the increasing number of experimental trials for translocation-associated RCCs, ${ }^{8,36,37}$ underscores the importance of correctly classifying paediatric RCCs. From the surgical pathologist's point of view, increased awareness of translocation-associated RCC is critical, as these tumours share significant morphological overlap with other subtypes, as is evident from our results. Morphologically, all of our translocationassociated RCCs focally mimicked other subtypes of RCC, in particular clear cell and papillary RCC. Previously described morphological features, including high-grade tumour cells with voluminous clear to granular cytoplasm, prominent cell borders and mixed architectural patterns ranging from a nested and trabecular growth pattern resembling clear cell RCC to focally prominent pseudoalveolar and papillary morphology, were present in four cases. Focally 
prominent psammoma bodies were also seen in two cases. These features were overall the most reliable morphological features for this diagnosis. ${ }^{9-11,17}$ However, two cases presented with morphology indistinguishable from clear cell RCC (case 5) and type 2 papillary RCC (case 6). The only clue to correct classification in these cases was the patient's young age.

All of these tumours either lacked or only weakly expressed cytokeratins and all demonstrated moderate to strong nuclear reactivity for TFE3 protein, which has previously been determined to be a sensitive and specific marker of TFE3 gene fusion. ${ }^{12}$ This marker was negative in all remaining cases. Our results suggest that any high-grade RCC presenting with variable features of clear cell and/or papillary morphology, prominent nested architecture, psammoma bodies, or unusual morphological features occurring in children and young adults should be worked up for cytokeratins and TFE3 to rule out this carcinoma.

In conclusion, our results suggest that RCC in children and young adults is a relatively rare disease that shares many histological similarities to RCC occurring in adults and yet demonstrates some unique clinicopathological differences. Xp11.2 translocationassociated RCC is a common and aggressive subtype in this age group and has heterogeneous and overlapping morphological characteristics, causing a significant risk of misclassification. Increased awareness and a high index of suspicion are key to the correct recognition of this entity.

\section{Acknowledgement}

We would like to thank Robin Kunkel for help with our figures.

\section{References}

1. Carcao M, Taylor G, Greenberg M et al. Renal-cell carcinoma in children: a different disorder from its adult counterpart? Med. Pediatr. Oncol. 1998; 31; 152-158.

2. Bruder E, Passera O, Harms D et al. Morphologic and molecular characterization of renal cell carcinoma in children and young adults. Am. J. Surg. Pathol. 2004; 28; 1117-1132.

3. Murphy WM, Grignon DJ, Perlman EJ eds. Tumors of the kidney, bladder and related urinary structures. Washington, DC: American Registry of Pathology, 2004.

4. Eble JN, Sauter G, Epstein JI, Sesterhenn IA eds. Pathology and genetics of tumours of the urinary system and male genital organs. Lyon: IARC Press, 2004.

5. Estrada C, Suthar A, Eaton S, Cilento B. Renal cell carcinoma: children's hospital Boston experience. Urology 2005; 66; 12961300.
6. Lack E, Cassady R, Sallan S. Renal cell carcinoma in childhood and adolescence: a clinical and pathological study of 17 cases. J. Urol. 1985; 133; 822-828.

7. Geller JI, Dome JS. Local lymph node involvement does not predict poor outcome in pediatric renal cell carcinoma. Cancer 2004; 101; 1575-1583.

8. Geller JI, Argani P, Adeniran A et al. Translocation renal cell carcinoma: lack of negative impact due to lymph node spread. Cancer 2008; 112; 1607-1616.

9. Argani P, Ladanyi M. Translocation carcinomas of the kidney. Clin. Lab. Med. 2005; 25; 363-378.

10. Argani P, Antonescu CR, Couturier J et al. PRCC-TFE3 renal carcinomas: morphologic, immunohistochemical, ultrastructural, and molecular analysis of an entity associated with the $\mathrm{t}(\mathrm{X} ; 1)(\mathrm{p} 11.2 ; \mathrm{q} 21)$. Am. J. Surg. Pathol. 2002; 26; 1553-1566.

11. Argani P, Antonescu CR, Illei PB et al. Primary renal neoplasms with the ASPL-TFE3 gene fusion of alveolar soft part sarcoma. Am. J. Pathol. 2001; 159; 179-192.

12. Argani P, Lal P, Hutchinson B, Lui MY, Reuter V, Ladanyi M. Aberrant nuclear immunoreactivity for TFE3 in neoplasms with TFE3 gene fusions. Am. J. Pathol. 2003; 27; 750-751.

13. Selle B, Furtwangler R, Graf N, Kaatsch P, Bruder E, Leuschner I. Population-based study of renal cell carcinoma in children in Germany, 1980-2005. Cancer 2006; 107; 2906-2914.

14. Indolfi $\mathrm{P}$, Terenziani $\mathrm{M}$, Casle $\mathrm{F}$ et al. Renal cell carcinoma in children: a clinicopathologic study. J. Clin. Oncol. 2003; 21; 530535.

15. Geller JI, Khoury J, Dome J. Local lymph node involvement does not predict poor outcome in pediatric renal cell carcinoma. Author's reply [letter]. Cancer 2005; 103; 1318.

16. Fuhrman S, Lasky L, Limas C. Prognostic significance of morphologic parameters in renal cell carcinoma. Am. J. Surg. Pathol. 1982; 6; 655-663.

17. Argani P, Ladanyi M. The evolving story of renal translocation carcinomas. Am. J. Clin. Pathol. 2006; 126; 332-334.

18. Greene FL, Page DL, Fleming ID et al. eds. AJCC cancer staging manual. New York, NY: Springer, 2002.

19. Oosterwijk E, Bander NH, Divgi C et al. Antibody localization in human renal cell carcinoma: a Phase I study of monoclonal antibody G250. J. Clin. Oncol. 1993; 11; 738-750.

20. Oosterwijk E, Ruiter D, Hoedemaeker P et al. Monoclonal antibody G250 recognizes a determinant present in renal-cell carcinoma and absent from normal kidney. Int. J. Cancer 1986; 38; 489-494.

21. Ivanov S, Liao S-Y, Ivanova A et al. Expression of hypoxiainducible cell-surface transmembrane carbonic anhydrases in human cancer. Am. J. Pathol. 2001; 158; 905-919.

22. Gobbo S, Eble JN, Grignon DJ et al. Clear cell papillary renal cell carcinoma: a distinct histopathologic and molecular genetic entity. Am. J. Surg. Pathol. 2008; 32; 1239-1245.

23. Kunju LP, Wojno K, Wolf JS, Cheng L, Shah RB. Papillary renal cell carcinoma with oncocytic cells and nonoverlapping low grade nuclei: expanding the morphologic spectrum with emphasis on clinicopathologic, immunohistochemical, and molecular features. Hum. Pathol. 2008; 39; 96-101.

24. Argani P, Lui MY, Couturier J, Bouvier R, Fournet J-C, Ladanyi M. A novel CLTC-TFE3 gene fusion in pediatric renal adenocarcinoma with $\mathrm{t}(\mathrm{X} ; 17)(\mathrm{p} 11.2 ; \mathrm{q} 23)$. Oncogene 2003; 22; 5374 5378 .

25. Huang F, Zwerdling T, Stern L, Ballard E, Warner B. Renal cell carcinoma as a secondary malignancy after treatment of acute promyelocytic leukemia. J. Pediatr. Hematol./ Oncol. 2001; 23; 609-611. 


\section{A Wu et al.}

26. Argani P, Lae M, Ballard E et al. Translocation carcinomas of the kidney after chemotherapy in childhood. J. Clin. Oncol. 2006; 24; 1529-1534.

27. Ramphal R, Pappo A, Zielenska M, Grant R, Ngan B-Y. Pediatric renal cell carcinoma: clinical, pathologic, and molecular abnormalities associated with the members of the MiT transcription factor family. Am. J. Clin. Pathol. 2006; 126; 349-364.

28. Rais-Bahrami S, Drabick JJ, De Marzo A et al. Xp11 translocation renal cell carcinoma: delayed but massive and lethal metastases of a chemotherapy-associated secondary malignancy. Urology 2007; 70; 178.e173-176.

29. Gelb AB, Shibuya RB, Weiss LM, Medeiros LJ. Stage I renal cell carcinoma: a clinicopathologic study of 82 cases. Am. J. Surg. Pathol. 1993; 17; 275-286.

30. Argani $\mathrm{P}$, Olgac $\mathrm{S}$, Tickoo $\mathrm{S}$ et al. Xp11 translocation renal cell carcinoma in adults: expanded clinical, pathologic, and genetic spectrum. Am. J. Surg. Pathol. 2007; 31; 1149-1160.

31. Meyer PN, Clark JI, Flanigan RC, Picken MM. Xp11.2 translocation renal cell carcinoma with very aggressive course in five adults. Am. J. Clin. Pathol. 2007; 128; 70-79.
32. Altinok G, Kattar M, Mohamed A, Poulik J, Grignon D, Rabah R. Pediatric renal carcinoma associated with Xp11.2 translocations/TFE3 gene fusions and clinicopathologic associations. Pediatr. Dev. Pathol. 2005; 8; 168-180.

33. Aronson D, Medary I, Finlay J, Herr H, Exelby P, La Quaglia M. Renal cell carcinoma in childhood and adolescence: retrospective survey for prognostic factors in 22 cases. J. Pediatr. Surg. 1996; 31; 183-186.

34. Dal Cin P, Stas M, Sciot R, De Wever I, Van Damme B, Van den Berghe $\mathrm{H}$. Translocation (X;1) reveals metastasis 31 years after renal cell carcinoma. Cancer Genet. Cytogenet. 1998; 101; 58-61.

35. Perot C, Bougaran J, Boccon-Gibod L et al. Two new cases of papillary renal cell carcinoma with $\mathrm{t}(\mathrm{X} ; 1)(\mathrm{p} 11 ; \mathrm{q} 21)$ in females. Cancer Genet. Cytogenet. 1999; 110; 54-56.

36. Garcia JA, Rini BI. Recent progress in the management of advanced renal cell carcinoma. CA Cancer J. Clin. 2007; 57; 112125.

37. Tsuda M, Davis IJ, Argani P et al. TFE3 fusions activate MET signaling by transcriptional up-regulation, defining another class of tumors as candidates for therapeutic MET inhibition. Cancer Res. 2007; 67; 919-929. 